\title{
PENGARUH HABITUASI, MEDIA SOSIAL DAN PEMBELAJARAN PENDIDIKAN KEWARGANEGARAAN TERHADAP KESADARAN LINGKUNGAN SISWA SMA NEGERI SE-KOTA BANDUNG
}

\author{
Oleh: Meidi Saputra*, dan Dasim Budimansyah
}

\begin{abstract}
The purpose of this research is to describe and analyze the effect of habituation, social media and Civic Education learning towards environmental awareness of senior high school students in Bandung. The hypothesis of this research is that there is the effect of habituation, social media, and Civic Education learning towards environmental awareness of senior high school in Bandung. The research was conducted by using explanatory survey method with two stage technique cluster random sampling. The research subjects are students of senior high school in Bandung. The research sample consisted of 98 students. Data were analyzed using path analysis. The findings in this research are, first, habituation, social media, and Civic Education learning in a positive and significant effect on environmental awareness with high category ( $R$ Square 0.676) contributed 67.6\% to the environmental awareness of students of senior high school in Bandung. Second, there is no significant relationship between gender with environmental awareness, majoring in environmental awareness, and parental employment status with environmental awareness.
\end{abstract}

Keywords: Habituation, Social Media, Civic Education Learning, Environmental Awareness

\section{PENDAHULUAN}

Dewasa ini, kehidupan umat manusia cenderung semakin kompleks dan bahkan cenderung mengarah kepada kondisi "chaostic". Disebut demikian karena (1) tetap meningkatnya pertumbuhan populasi dunia yang melebihi kapasitas produktivitas natural bumi, (2) perkembangan komunikasi dan transportasi yang cepat sehingga menghasilkan "world interlinkages" seperti globalisasi ekonomi, perdagangan, krisis lingkungan, masalah pembangunan, kemiskinan dan lain-lain. (Sudibyo, 2008, hlm. 2).

Krisis lingkungan sedang dialami masyarakat dunia tidak terkecuali Kota Bandung. Kota Bandung yang merupakan ibukota dari provinsi Jawa Barat, beberapa waktu lalu mendapat sorotan dari mediamedia yang ada di Indonesia akibat dijuluki

\footnotetext{
* Mahasiswa Pendidikan Kewarganegaraan SPs Universitas Pendidikan Indonesia. E-mail: saputrameidi@yahoo.co.id

- Mahasiswa Pendidikan Kewarganegaraan SPs Universitas Pendidikan Indonesia
} 
sebagai "The City of Pigs". Adalah Inna Savova, seorang blogger Bulgaria yang menetap di Kota Bandung, yang melabeli julukan tersebut. Menurutnya perilaku warga Kota Bandung cenderung tidak peduli terhadap kebersihan lingkungan kota mereka. Mulai dari membuang sampah sembarangan, tong sampah yang banyak yang dicuri, hingga tikus yang berkeliaran di sekitar rumah (detikNews, 5 Februari 2014).

Permasalahan ini mengerucut pada suatu fakta besar bahwa kesadaran manusia dalam menjaga lingkungannya belum terlaksana dengan baik. Hal itu dibuktikan dengan sikap dan interaksi manusia terhadap lingkungannya. Rendahnya kesadaran masyarakat terhadap lingkungan hidup menyebabkan banyaknya kejadian yang merugikan baik secara langsung maupun tidak langsung. Siahaan (dalam Prasetyo, 2013, hlm. 2) menegaskan bahwa manusia adalah faktor terbesar yang "berkontribusi" terkait perusakan lingkungan dibandingkan faktor alam itu sendiri. Seiring dengan perkembangan zaman pula mengubah pola pikir dan perilaku dari sifat manusia itu sendiri. Ini terbukti kesadaran dari manusia itu sendiri kurang diterapkan dalam diri masingmasing individu. Kompleksitas permasalahan diatas tidak boleh dibiarkan begitu saja. Beranjak dari permasalahan tersebut, maka perlunya membangun kesadaran lingkungan pada masyarakat untuk menjaga sekaligus melestarikan lingkungan hidupnya.

Kesadaran membentuk sifat manusia menjadi lebih baik, dari adanya rasa sadar menjadikan kehidupan yang lebih baik dari sebelumnya. Manusia dapat membangun rasa sadar itu dengan mengetahui bahwa manusia adalah bagian daripada alam. Pondasi kesadaran yang kuat menjadi dasar dari membangun rasa kesadaran ditambah kebiasaan kebiasaan yang baik maka semakin dekatlah manusia dengan kesadaran itu (Prasetyo, 2013, hlm. 6). Kesadaran merupakan cara berpikir yang ada di dalam masyarakat, jika masyarakat menghendaki suatu perubahan maka cara berpikir yang ada dalam masyarakat harus diubah. Dan untuk merubah cara berpikir tersebut maka merubah diri sendiri merupakan suatu keharusan bagi masyarakat yang menginginkan perubahan (Darmawan, dkk. 2009, hlm. 104).

Kesadaran dalam diri individu dapat tumbuh dengan tiga cara yakni mengenal diri sendiri, komunikasi dan tanggung jawab. Dengan mengenal diri sendiri dengan baik berarti meningkatkan kualitas 
kehidupan sehingga menimbulkan kesadaran, demikian halnya dengan berkomunikasi maka hal-hal yang tidak diketahui menjadi tahu sehingga menjadi sadar sedangkan dengan bertanggung jawab maka akan menimbulkan kesadaran akan pentingnya sesuatu. Soekanto mengemukakan ada empat indikator kesadaran yang masing-masing merupakan suatu tahapan bagi tahapan berikutnya dan menunjuk pada tingkat kesadaran tertentu mulai dari yang terendah sampai dengan yang tertinggi, antara lain: pengetahuan, pemahaman, sikap, pola perilaku (tindakan). Sementara Benyamin Bloom, seorang ahli psikologi pendidikan membaginya kedalam 3 (tiga) domain, ranah atau kawasan yakni: a) kognitif (cognitive), b) afektif (affective), c) psikomotor (psychomotor) (Jamanti, 2014, hlm. 24).

Kesadaran lingkungan adalah pengertian yang mendalam pada orang seorang atau sekelompok orang yang terwujud dalam pemikiran, sikap, dan tingkah laku yang mendukung pengembangan lingkungan. Kesadaran lingkungan terlihat dari perubahan pemikiran, sikap, dan perilaku yang mendukung pengembangan lingkungan (Kamus Besar Bahasa Indonesia (2005, hlm. 975). Menurut Swan dan Stapp (dalam
Darmawan, dkk, 2009, hlm. 104), kesadaran terhadap lingkungan merupakan bentuk kepedulian seseorang terhadap kualitas lingkungan, sehingga muncul berbagai aksi menentang kebijaksanaan yang tidak berwawasan lingkungan.

Kompleksitas permasalahan yang timbul pada masyarakat Kota Bandung tersebut tidak boleh dibiarkan begitu saja. Beranjak dari permasalahan tersebut, maka diperlukan suatu langkah solutif untuk mengatasi permasalahan ini. Salah satu cara untuk mengatasi permasalahan tersebut adalah dengan mengedukasi masyarakat itu sendiri atau dengan kata lain masyarakat diberikan pendidikan. Dipilihnya pendidikan sebagai cara untuk mengatasi permasalahan tersebut, karena pendidikan masih dianggap sebagai instrumen yang efektif dan "more sustainably developed".

Lalu pendidikan seperti apa yang dapat memperbaiki kesalahan perilaku dan kesalahan pandang tersebut? Salah satunya adalah melalui Pendidikan Kewarganegaraan. Pendidikan Kewarganegaraan dianggap mampu untuk merubah cara pandang dan perilaku manusia atau warga negara dalam mengelola krisis yang ada di lingkungannya. Pengembangan Pendidikan Kewarganegaraan menjadi kurikulum yang 
bertujuan mendidik agar warga negara mampu mengelola krisis berkaitan erat dengan pengembangan karakteristik warga negara yang disampaikan Cogan (1998). Cogan mengidentifikasi delapan karakteristik yang perlu dimiliki warga Negara sehubungan dengan semakin beratnya tantangan yang harus dihadapi dimasa mendatang. Karakteristik warga negara tersebut meliputi:

1. Kemampuan mengenal dan mendekati masalah sebagai warga Negara masyarakat global;

2. Kemampuan bekerjasama dengan orang lain dan memikul tanggung jawab atas peran atau kewajibannya dalam masyarakat;

3. Kemampuan untuk memahami, menerima, dan menghormati perbedaan-perbedaan budaya;

4. Kemampuan berfikir kritis dan sistematis;

5. Kemauan menyelesaikan konflik dengan cara damai tanpa kekerasan;

6. Kemauan mengubah gaya hidup dan pola makanan pokok yang sudah bisa, guna melindungi lingkungan hidup;
7. Memiliki kepekaan terhadap dan mempertahankan hak azasi manusia (seperti hak kaum wanita, minoritas etnis, dsb.);

8. Kemauan dan kemampuan berpartisipasi dalam kehidupan politik pada tingkatan pemerintahan lokal, nasional, dan internasional (Sapriya dan Winataputra, 2004, hlm. 9).

Winataputra dan Budimansyah (2007, hlm. 29) berpendapat agar pengembangan

Pendidikan Kewarganegaraan dapat berjalan sebagaimana mestinya, seyogyanya Pendidikan Kewarganegaraan harus memiliki jati diri; diorganisasikan secara lintas bidang ilmu; difasilitasi dengan pembelajaran yang bersifat partisipatif dan interaktif; isi dan prosesnya dikaitkan pada kehidupan nyata; diselenggarakan dalam situasi yang demokratis; diupayakan agar mewadahi keanekaragaman sosial budaya masyarakat; dan dikembangkan bersama secara kolaboratif oleh sekolah, orang tua dan masyarakat termasuk pemerintah.

Untuk mewujudkan warga negara yang mampu mengelola krisis, maka diperlukannya rekayasa dari pembelajaran Pendidikan Kewarganegaraan itu sendiri. Rekayasa yang diperlukan dalam 
pendidikan Kewarganegaraan itu menurut Djahiri (2011, hlm. 2) berupa komponen pembelajaran yang terdiri dari materi, metode, media, sumber dan evaluasi pembelajaran harus disusun sedemikian rupa. Harapannya setelah komponen pembelajaran Pendididkan Kewarganegaraan direkayasa sedemikian rupa, siswa berkembang menjadi warga negara yang mampu mengelola krisis pada lingkungan di sekitar mereka.

\section{Penandatanganan kesepakatan} bersama tentang pendidikan lingkungan hidup (PLH) antara Kementerian Pendidikan dan Kebudayaan Nasional dan Kementerian Lingkungan Hidup telah membawa harapan dalam mendukung proses membangun kesadaran lingkungan pada masyarakat khususnya masyarakat yang berada pada usia sekolah. Dalam sambutannya, menteri lingkungan hidup, mengatakan bahwa "tujuan utama dari kesepakatan tersebut terintegrasinya mata pelajaran sekolah dengan pendidikan lingkungan hidup untuk mewujudkan perilaku dan berbudaya lingkungan hidup".

Untuk menumbuhkan dan menanamkan kesadaran lingkungan, maka dalam prosesnya pembelajaran Pendidikan Kewarganegaraan perlu diiringi dengan proses habituasi (pembiasaan) yang sesuai dengan pelestarian lingkungan hidup. Pentingnya proses habituasi terhadap nilainilai tersebut dilandasi dengan pemikiran

Di sisi lain, Pemerintah Kota Bandung merespon cepat permasalahan lingkungan yang terjadi di daerahnya. Melalui instruksi walikota, dalam hal ini Bapak Ridwan Kamil, pemerintah Kota Bandung banyak mengeluarkan kebijakan atau program yang berwawasan lingkungan. Salah satu program berwawasan lingkungan yang dibuat untuk membangun kebiasaan (habit) masyarakat Kota Bandung terhadap pelestarian lingkungan hidup adalah aksi "Gerakan Pungut Sampah (GPS)". Gerakan Pungut Sampah (GPS) adalah suatu aksi yang memberikan keteladanan, memberikan motivasi kepada masyarakat/orang lain untuk menciptakan lingkungan yang bebas sampah, membentuk masyarakat agar menjaga lingkungan bebas sampah dan menempatkan sampah sesuai dengan kategorinya pada tempat yang diperuntukkannya. Gerakan ini juga dilakukan untuk menjaga dan menegakkan perda K3 Kota Bandung (BPLH Kota Bandung). 
Gerakan Pungut sampah merupakan program untuk mengubah kultur masyarakat untuk lebih mencintai Kota Bandung. Perubahan kultur dari yang biasanya cuek, biasanya buang sampah sembarangan, kultur yang biasa pasif menjadi aktif untuk mencintai kebersihan. Gerakan Pungut Sampah adalah salah satu upaya yang dilakukan pemerintah Kota Bandung supaya masyarakat membiasakan diri untuk menjaga kebersihan di lingkungannya dengan cara menyediakan waktu 10 hingga 30 menit untuk memungut sampah di lingkungan sekitar. Gerakan ini secara formal dilakukan setiap hari senin, rabu dan jum'at (Kompas, 23 Juni 2014).

Berdasarkan latar belakang di atas maka penulis tertarik mengadakan penelitian dengan judul tesis tesis ini dengan judul "Pengaruh Habituasi, Media Sosial dan Pembelajaran Pendidikan Kewarganegaraan terhadap Kesadaran Lingkungan Siswa SMA Negeri Se-Kota Bandung”.

\section{RUMUSAN MASALAH}

Berdasarkan pada latar belakang masalah di atas maka penulis mengajukan rumusan masalah pokok penelitian ini, yaitu: Bagaimanakah pengaruh proses habituasi, media sosial dan pembelajaran
Pendidikan Kewarganegaraan terhadap kesadaran lingkungan pada siswa SMA Negeri di Kota Bandung?

\section{TUJUAN PENELITIAN}

Secara umum penelitian ini bertujuan untuk mendeskripsikan dan menganalisis pengaruh proses habituasi, media sosial dan pembelajaran Pendidikan Kewarganegaraan terhadap kesadaran lingkungan pada siswa SMA Negeri di Kota Bandung

\section{HIPOTESIS PENELITIAN}

"Terdapat pengaruh habituasi, media sosial, dan pembelajaran Pendidikan Kewarganegaraan terhadap kesadaran lingkungan pada siswa SMA Negeri di Kota Bandung”.

\section{METODE}

Penelitian tentang pengaruh pembelajaran Pendidikan Kewarganegaraan terhadap kesadaran lingkungan siswa SMA ini menggunakan pendekatan kuantitatif. Adapun metode penelitian yang digunakan dalam penelitian ini adalah metode survey eksplanatori (explanatory methode) yaitu suatu metode penelitian yang bermaksud menjelaskan 
hubungan antar variabel dengan menggunakan pengujian hipotesis.

Pengertian penelitian survey menurut Singarimbun dalam (Effendi \& Tukiran, 2012, hlm. 3) adalah penelitian yang mengambil sampel dari suatu populasi dan menggunakan kuesioner sebagai alat pengumpul data yang pokok. Tujuan dari penelitian explanatory adalah untuk menjelaskan atau menguji hubungan antar variabel yang diteliti.

Populasi (universum, universe, universe of discourse) adalah jumlah total dari seluruh unit atau elemen dimana penyelidik tertarik (Silalahi, 2010, hlm. 253). Menurut Riduwan (2008, hlm. 37) populasi adalah wilayah generalisasi yang terdiri dari objek atau subjek yang menjadi kuantitas dan karakteristik tertentu yang ditetapkan oleh peneliti untuk mempelajari dan kemudian ditarik kesimpulannya. Sedangkan menurut Margono (2009, hlm. 118), populasi adalah seluruh data yang menjadi perhatian dalam suatu ruang lingkup dan waktu yang ditentukan. Populasi penelitian ini adalah SMA Negeri Se-Kota Bandung yang Berwawasan Lingkungan. Teknik pengambilan sampel menggunakan teknik Multi Stage Cluster Random Sampling.
Dalam penelitian ini, analisis data yang digunakan adalah path analysis (analisis jalur). Menurut Gall, gall dan Borg "Path analysis is method for testing the validity of the theory about causal relationship between three or more variables that have been studied using correlational research design"(Analisis Jalur adalah metode untuk mengukur validitas dari teori mengenai hubungan kausal antara tiga atau lebih variabel yang dapat dipelajari menggunakan rancangan penelitian korelasi) (Kusnendi, 2008, hlm. 146).

\section{HASIL}

\section{Uji Hipotesis}

\section{Hipotesis Statistik}

Ho : $\beta_{1}=0:$ habituasi, media sosial dan pembelajaran PKn tidak berpengaruh signifikan secara simultan terhadap kesadaran lingkungan.

Ha $: \beta_{1} \neq 0 \quad$ : habituasi, media sosial dan pembelajaran PKn tidak berpengaruh signifikan secara simultan terhadap kesadaran lingkungan. 
Untuk menguji hipotesis diatas digunakan uji $\mathrm{F}$ dengan formula sebagai berikut:

$$
F=\frac{R^{2}(n-k-1)}{k\left(1-R^{2}\right)}
$$

Berdasarkan hasil pengolahan menggunakan software SPSS for windows diperoleh nilai $F_{\text {hitung }}$ pengaruh habituasi, media sosial dan pembelajaran $\mathrm{PKn}$ terhadap kesadaran lingkungan sebagai berikut:

\section{Tabel}

Pengujian Simultan Sub Struktur Ke-2

\begin{tabular}{|c|c|c|c|c|c|c|}
\hline \multicolumn{7}{|c|}{ ANOVA } \\
\hline \multicolumn{2}{|c|}{ Model } & $\begin{array}{l}\text { Sum of } \\
\text { Squares }\end{array}$ & df & Mean Square & $\mathrm{F}$ & Sig. \\
\hline \multirow[t]{3}{*}{1} & Regression & 15,797 & 3 & 5,266 & 65,259 &, $000^{a}$ \\
\hline & Residual & 7,585 & 94 & 081 & & \\
\hline & Total & 23,382 & 97 & & & \\
\hline
\end{tabular}

a. Predictors: (Constant), pembelajaran PKn, media sosial, habituasi

b. Dependent Variable: kesadaran lingkungan

Berdasarkan tabel pengujian diatas dapat dilihat nilai $F_{\text {hitung }}$ sebesar 65,259. Sementara dari tabel $F$ untuk tingkat signifikansi 0.05 dan derajat bebas (2;98-31) diperoleh F $0,05(3 ; 09)=(3,09)$. Karena nilai $F_{\text {hitung }}(65,259)>F_{\text {tabel }}(3,09)$ maka pada tingkat kekeliruan 5\% maka $\mathrm{H} 0$ ditolak dan $\mathrm{H} 1$ diterima. Berdasarkan hasil pengujian dengan tingkat kepercayaan $95 \%$ disimpulkan bahwa habituasi, media sosial dan pembelajaran PKn secara bersamasama berpengaruh signifikan terhadap kesadaran lingkungan.

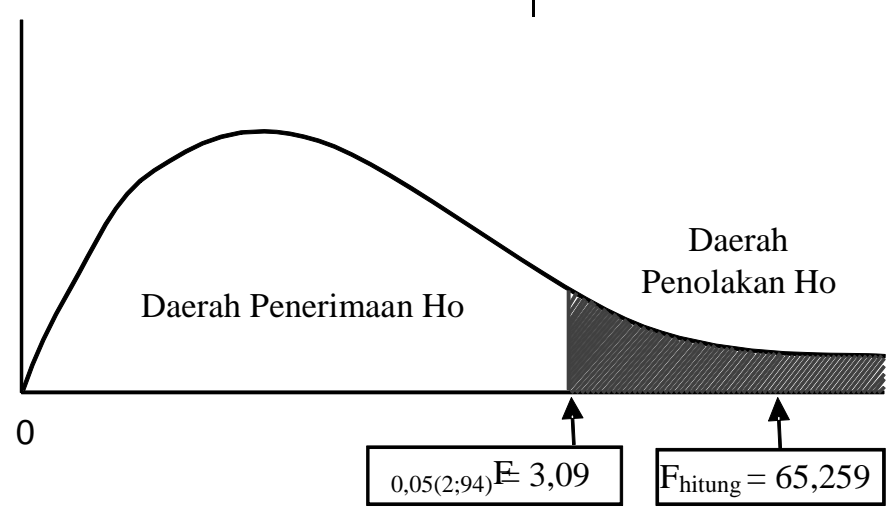

\section{Gambar 4.2}


Daerah Penerimaan dan Penolakan Ho Pada Uji Simultan

Pengaruh Habituasi, Media Sosial dan Pembelajaran PKn Terhadap Kesadaran Lingkungan

Pada gambar diatas dapat dilihat Fhitung sebesar 65,259 berada pada daerah penolakan Ho, yang menunjukkan bahwa habituasi, media sosial dan pembelajaran

\begin{tabular}{|l|l|}
\hline Variabel & Koefisien Jalur \\
\hline Habituasi (X1) & $\rho_{\mathrm{yx} 1}=0.308$ \\
\hline Media Sosial (X2) & $\rho_{\mathrm{yx} 2}=0.246$ \\
\hline
\end{tabular}

Dengan memperhatikan tabel di atas, maka diperoleh persamaan jalur sebagai berikut :

$Y=0.308 X_{1}+0.246 X_{2}+\varepsilon_{1}$
PKn secara bersama-sama berpengaruh signifikan terhadap kesadaran lingkungan.

Analisis Jalur (Path Analysis)

a. Koefisien Jalur Sub Struktur ke-1

Tabel 1

Besaran Koefisien Jalur Sub Struktur ke-1 


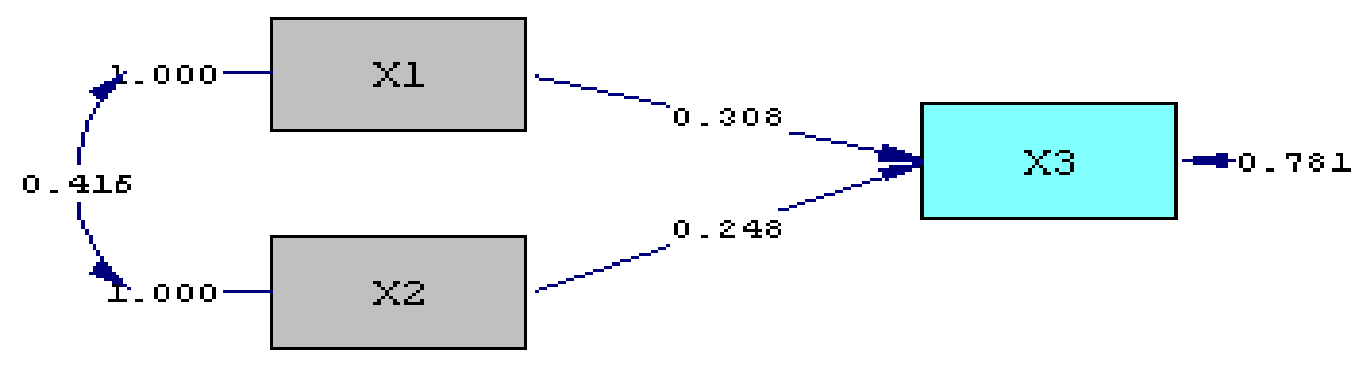

\section{Gambar 1}

\section{Koefisien Jalur Sub Struktur Ke-1}

\section{b. Koefisien Jalur Sub Struktur ke-2}

\section{Tabel 2}

\section{Besaran Koefisien Jalur Struktur ke-2}

\begin{tabular}{|l|l|}
\hline Variabel & Koefisien Jalur \\
\hline Habituasi (X1) & $\rho_{\mathrm{yx} 1}=0.547$ \\
\hline Media Sosial (X2) & $\rho_{\mathrm{yx} 2}=0.236$ \\
\hline Pembelajaran PKn (X3) & $\rho_{\mathrm{yx} 3}=0.244$ \\
\hline
\end{tabular}

Dengan memperhatikan tabel di atas, maka diperoleh persamaan jalur sebagai berikut :

$Y=0.547 X_{1}+0.236 X_{2}+0.244 X_{3}+\varepsilon_{1}$

Nilai koefisien jalur variabel habituasi lebih besar dibandingkan koefisien jalur variabel media sosial dan pembelajaran PKn artinya habituasi lebih menentukan (berpengaruh lebih besar) terhadap kesadaran lingkungan dibandingkan media sosial dan pembelajaran PKn baik secara langsung maupun tak langsung. 


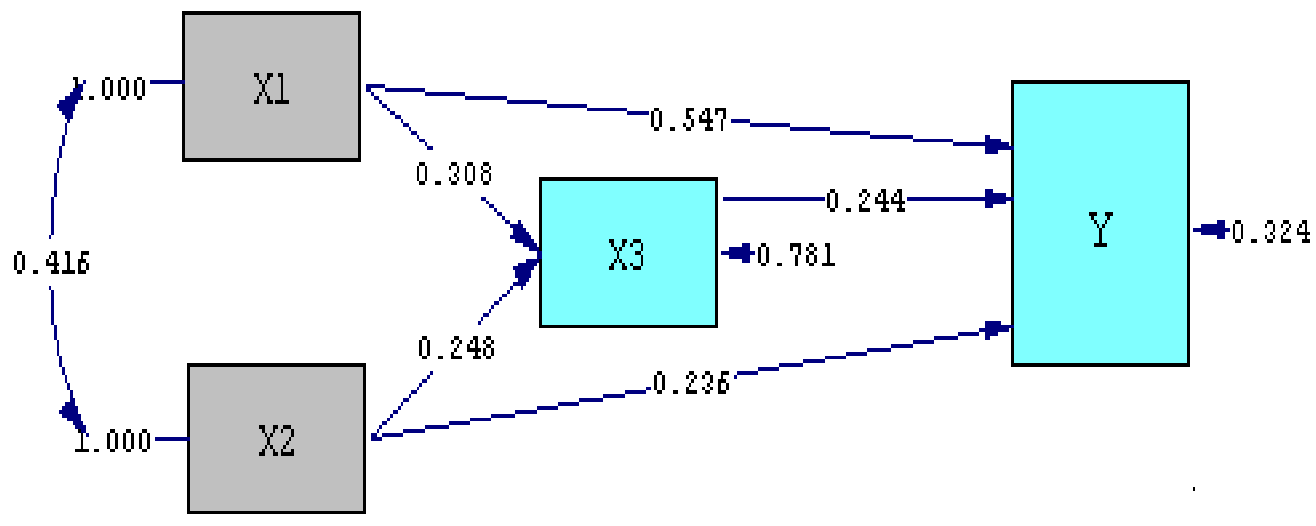

\section{Gambar 2}

\section{Koefisien Jalur Sub Struktur Ke-2}

\section{Analisis Kontribusi}

Analisis kontribusi dilakukan untuk melihat pengaruh langsung dan tidak langsung dari masing-masing variable terhadap variable terikat.

\section{a. Sub Struktur ke-1}

1) Pengaruh habituasi terhadap pembelajaran PKn secara langsung: $(0,308)^{2}=0,095=9,5 \%$

2) Pengaruh habituasi terhadap pembelajaran PKn secara tidak langsung: $(0,308 \times 0,416)=0,032=$ $3,2 \%$

3) Pengaruh media sosial terhadap pembelajaran PKn secara langsung: $(0,248)^{2}=0,062=6,2 \%$

4) Pengaruh media sosial terhadap pembelajaran PKn secara tidak langsung: $(0,308 \times 0,416)=0,032=$ $3,2 \%$

5) Total kontribusi habituasi dan media sosial terhadap pembelajaran PKn adalah $21,9 \%$ 


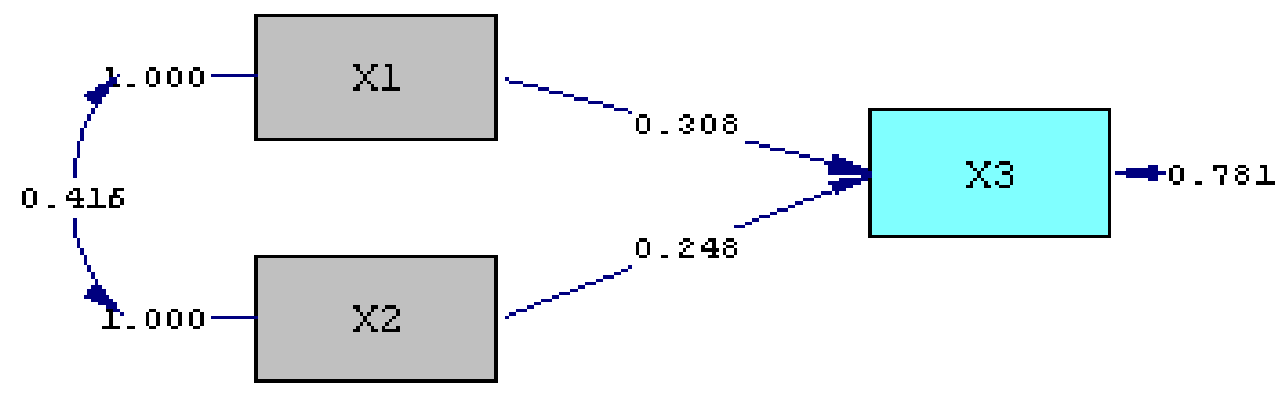

\section{Gambar 3}

\section{Besaran Kontribusi Sub Struktur Ke-1}

\section{b. Sub Struktur ke-2}

1) Pengaruh habituasi terhadap kesadaran lingkungan secara langsung $=(0,547)^{2}=$ $0,299=29.9 \%$

2) Pengaruh habituasi terhadap kesadaran lingkungan secara tidak langsung melalui media sosial $=(0,547 \times 0,416 \mathrm{x}$ $0,236)=0,054=5,4 \%$

3) Pengaruh habituasi terhadap kesadaran lingkungan secara tidak langsung melalui pembelajaran $\mathrm{PKn}=(0,236 \mathrm{x}$ $0,410 \times 0,244)=0,055=5,5 \%$

4) Pengaruh media sosial terhadap kesadaran lingkungan secara langsung= $(0,236)^{2}=0,056=5,6 \%$

5) Pengaruh media sosial terhadap kesadaran lingkungan secara tidak langsung melalui habituasi $=(0,547 \mathrm{x}$ $0,416 \times 0,236)=0,054=5,4 \%$
6) Pengaruh media sosial terhadap kesadaran lingkungan secara tidak langsung melalui pembelajaran $\mathrm{PKn}=$ $(0,236 \times 0,375 \times 0,244)=0,022=2,2 \%$

7) Pengaruh pembelajaran PKn terhadap kesadaran lingkungan secara langsung $=$ $(0,244)^{2}=0,060=6 \%$

8) Pengaruh pembelajaran PKn terhadap kesadaran lingkungan secara tidak langsung melalui habituasi $=(0,236 \mathrm{x}$ $0,410 \times 0,244)=0,055=5,5 \%$

9) Pengaruh pembelajaran PKn terhadap kesadaran lingkungan secara tidak langsung melalui media sosial $=(0,236$ $\mathrm{x} 0,375 \times 0,244)=0,022=2,2 \%$

10) Total kontribusi habituasi, media sosial dan pembelajaran $\mathrm{PKn}$ terhadap kesadaran lingkungan adalah $67,6 \%$ 


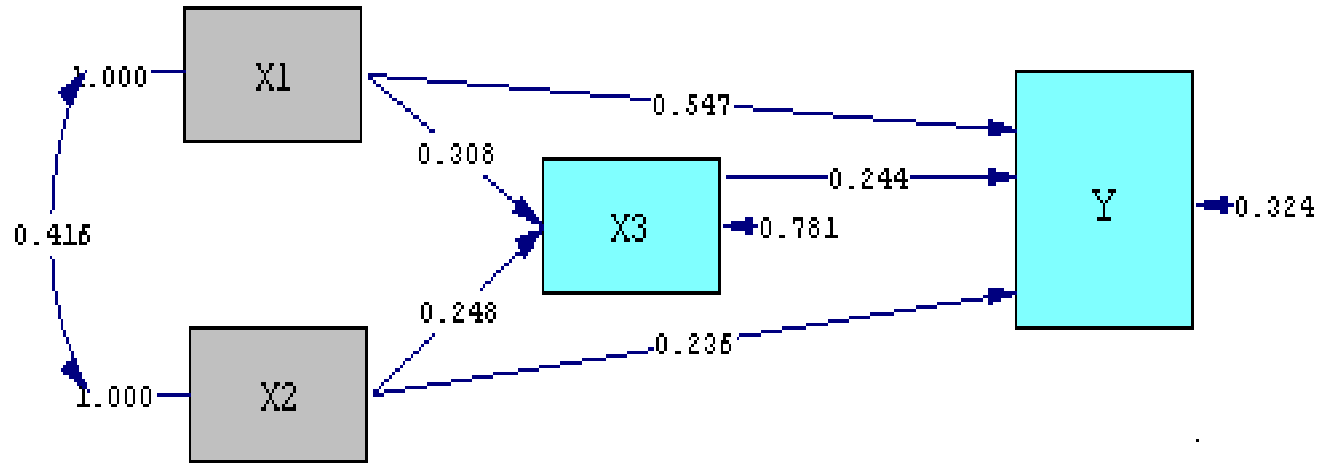

Gambar 4

Besaran Kontribusi Sub Struktur Ke-2

Gambaran Keseluruhan Penelitian

\begin{tabular}{|l|l|l|l|l|l|l|l|}
\hline $\begin{array}{l}\text { Pengaruh } \\
\text { Variabel }\end{array}$ & R & $\begin{array}{l}\text { Langsun } \\
\text { g }\end{array}$ & $\begin{array}{l}\text { Tidak } \\
\text { langsun } \\
\text { g }\end{array}$ & Total & Uji t/ & Sig & Keteranga \\
Uji F & & \\
\hline $\begin{array}{l}\text { X1, X2, X3 - } \\
\text { Y }\end{array}$ & 0,822 & $67,6 \%$ & - & $67,6 \%$ & 65,259 &, 000 & Signifikan \\
\hline
\end{tabular}




\section{Uji Chi Square}

a. Tabulasi Silang antara Jenis Kelamin dengan Kesadaran Lingkungan

\section{Tabel 3}

Tabulasi Silang Antara Jenis Kelamin dengan Kesadaran Lingkungan

\begin{tabular}{|c|c|c|c|c|c|c|c|c|}
\hline \multirow{2}{*}{\multicolumn{2}{|c|}{ Jenis Kelamin }} & \multicolumn{5}{|c|}{ Kesadaran Lingkungan } & \multirow[b]{2}{*}{ Total } & \multirow{2}{*}{$\begin{array}{l}\text { Chi } \\
\text { Square } \\
\text { Prob }\end{array}$} \\
\hline & & \multirow{2}{*}{$\begin{array}{l}\text { SR } \\
3\end{array}$} & \multirow{2}{*}{$\begin{array}{l}\mathbf{R} \\
14\end{array}$} & \multirow{2}{*}{$\begin{array}{l}\mathbf{S} \\
15\end{array}$} & \multirow{2}{*}{$\begin{array}{l}\mathbf{T} \\
10\end{array}$} & \multirow{2}{*}{$\begin{array}{l}\text { ST } \\
3\end{array}$} & & \\
\hline Ir: I I: & $\mathrm{F}$ & & & & & & 45 & \multirow{6}{*}{0,589} \\
\hline 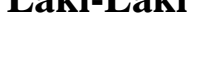 & $\%$ & 6,7 & 31,1 & 33,3 & 22,2 & 6,7 & 100,0 & \\
\hline \multirow{2}{*}{ Perempuan } & $\mathrm{F}$ & 8 & 15 & 12 & 14 & 4 & 53 & \\
\hline & $\%$ & 15,1 & 28,3 & 22,6 & 26,4 & 7,5 & 100,0 & \\
\hline \multirow{2}{*}{ Total } & $\mathrm{F}$ & 11 & 29 & 27 & 24 & 7 & 98 & \\
\hline & $\%$ & 11,2 & 29,6 & 27,6 & 24,5 & 7,1 & 100,0 & \\
\hline
\end{tabular}

b. Tabulasi Silang antara Jurusam dengan Kesadaran Lingkungan

\section{Tabel 4}

Tabulasi Silang Antara Jurusan dengan Kesadaran Lingkungan

\begin{tabular}{|c|c|c|c|c|c|c|c|c|}
\hline \multirow{2}{*}{\multicolumn{2}{|c|}{ Jurusan }} & \multicolumn{5}{|c|}{ Kesadaran Lingkungan } & \multirow{2}{*}{ Total } & \multirow{2}{*}{$\begin{array}{l}\text { Chi Square } \\
\text { Prob }\end{array}$} \\
\hline & & SR & $\mathbf{R}$ & $\mathbf{S}$ & $\mathbf{T}$ & ST & & \\
\hline \multirow{2}{*}{ IPA } & $\mathrm{F}$ & 4 & 11 & 15 & 16 & 4 & 50 & \multirow{6}{*}{0,230} \\
\hline & $\%$ & 8,0 & 22,0 & 30,0 & 32,0 & 8,0 & 100,0 & \\
\hline \multirow{2}{*}{ IPS } & $\mathrm{F}$ & 7 & 18 & 12 & 8 & 3 & 48 & \\
\hline & $\%$ & 14,6 & 37,5 & 25,0 & 16,7 & 6,3 & 100,0 & \\
\hline \multirow{2}{*}{ Total } & $\mathrm{F}$ & 11 & 29 & 27 & 24 & 7 & 98 & \\
\hline & $\%$ & 11,2 & 29,6 & 27,6 & 24,5 & 7,1 & 100,0 & \\
\hline
\end{tabular}




\section{c. Tabulasi Silang antara Pekerjaan Orang Tua dengan Kesadaran Lingkungan}

\section{Tabel 5}

Tabulasi Silang Antara Pekerjaan Orangtua dengan Kesadaran Lingkungan

\begin{tabular}{|c|c|c|c|c|c|c|c|c|}
\hline \multirow{2}{*}{\multicolumn{2}{|c|}{$\begin{array}{l}\text { Status Pekerjaan } \\
\text { Orangtua }\end{array}$}} & \multicolumn{5}{|c|}{ Kesadaran Lingkungan } & \multirow[b]{2}{*}{ Total } & \multirow{2}{*}{$\begin{array}{l}\text { Chi } \\
\text { Square } \\
\text { Prob }\end{array}$} \\
\hline & & \multirow{2}{*}{$\begin{array}{l}\text { SR } \\
9\end{array}$} & \multirow{2}{*}{$\begin{array}{l}\mathbf{R} \\
12\end{array}$} & \multirow{2}{*}{$\begin{array}{l}\mathbf{S} \\
11\end{array}$} & \multirow{2}{*}{$\begin{array}{l}\mathbf{T} \\
11\end{array}$} & \multirow{2}{*}{$\begin{array}{l}\text { ST } \\
3\end{array}$} & & \\
\hline \multirow{2}{*}{ Wiraswasta } & $\mathrm{F}$ & & & & & & 46 & \multirow{10}{*}{0,390} \\
\hline & $\%$ & 19,6 & 26,1 & 23,9 & 23,9 & 6,5 & 100,0 & \\
\hline \multirow{2}{*}{ PNS } & $\mathrm{F}$ & 0 & 6 & 5 & 6 & 3 & 20 & \\
\hline & $\%$ & 0,0 & 30,0 & 25,0 & 30,0 & 15,0 & 100,0 & \\
\hline \multirow{2}{*}{ Karyawan } & $\mathrm{F}$ & 0,0 & 3,0 & 3,0 & 4,0 & 0,0 & 10,0 & \\
\hline & $\%$ & 0,0 & 30,0 & 30,0 & 40,0 & 0,0 & 100,0 & \\
\hline \multirow{2}{*}{ Profesi } & $\mathrm{F}$ & 2,0 & 8,0 & 8,0 & 3,0 & 1,0 & 22,0 & \\
\hline & $\%$ & 9,1 & 36,4 & 36,4 & 13,6 & 4,5 & 100,0 & \\
\hline \multirow{2}{*}{ Total } & $\mathrm{F}$ & 11 & 29 & 27 & 24 & 7 & 98 & \\
\hline & $\%$ & 11,2 & 29,6 & 27,6 & 24,5 & 7,1 & 100,0 & \\
\hline
\end{tabular}

\section{PEMBAHASAN}

Berdasarkan pengujian hipotesis penelitian menunjukkan bahwa proses habituasi, media sosial, dan pembelajaran Pendidikan Kewarganegaraan berkorelasi positif dan memberikan pengaruh yang signifikan terhadap kesadaran lingkungan. Persentase pengaruh habituasi, media sosial dan pembelajaran Pendidikan Kewarganegaraan terhadap kesadaran lingkungan adalah sebesar 67,6\%. Hal ini menunjukkan bahwa proses habituasi, media sosial, dan pembelajaran Pendidikan Kewarganegaraan berkontribusi besar dalam upaya menumbuhkan kesadaran lingkungan.

Terkait hal tersebut Parker, dkk (dalam Winataputra \& Budimansyah, 2007, hlm. 1) mengemukakan bahwa pendidikan kewarganegaraan perlu dikembangkan dalam bentuk "...a curriculum geared to the development of world citizens who are capale of dealing with the crises" yakni seperangkat kurikulum yang diarahkan 
pada pengembangan warga dunia yang mampu mengelola krisis.

\section{Pengembangan \\ Pendidikan}

Kewarganegaraan menjadi kurikulum yang bertujuan mendidik agar warga negara mampu mengelola krisis berkaitan erat dengan pengembangan karakteristik warga negara yang disampaikan Cogan (1998). Cogan mengidentifikasi delapan karakteristik yang perlu dimiliki warga Negara sehubungan dengan semakin beratnya tantangan yang harus dihadapi dimasa mendatang. Karakteristik warga negara tersebut meliputi:

1. Kemampuan mengenal dan mendekati masalah sebagai warga Negara masyarakat global;

2. Kemampuan bekerjasama dengan orang lain dan memikul tanggung jawab atas peran atau kewajibannya dalam masyarakat;

3. Kemampuan untuk memahami, menerima, dan menghormati perbedaan-perbedaan budaya;

4. Kemampuan berfikir kritis dan sistematis;

5. Kemauan menyelesaikan konflik dengan cara damai tanpa kekerasan;
6. Kemauan mengubah gaya hidup dan pola makanan pokok yang sudah bisa, guna melindungi lingkungan hidup;

7. Memiliki kepekaan terhadap dan mempertahankan hak azasi manusia (seperti hak kaum wanita, minoritas etnis, dsb.);

8. Kemauan dan kemampuan berpartisipasi dalam kehidupan politik pada tingkatan pemerintahan lokal, nasional, dan internasional (Sapriya dan Winataputra, 2004, hlm. 9).

Untuk mewujudkan warga negara yang mampu mengelola krisis, maka diperlukannya rekayasa dari pembelajaran Pendidikan Kewarganegaraan itu sendiri. Rekayasa yang diperlukan dalam pendidikan Kewarganegaraan itu menurut Djahiri (2011, hlm. 2) berupa komponen pembelajaran yang terdiri dari materi, metode, media, sumber dan evaluasi pembelajaran harus disusun sedemikian rupa. Harapannya setelah komponen pembelajaran Pendididkan Kewarganegaraan direkayasa sedemikian rupa, siswa berkembang menjadi warga negara yang mampu mengelola krisis pada lingkungan di sekitar mereka. 
Untuk menumbuhkan dan menanamkan kesadaran lingkungan, maka dalam prosesnya pembelajaran Pendidikan Kewarganegaraan perlu diiringi dengan proses habituasi (pembiasaan) yang sesuai dengan pelestarian lingkungan hidup. Menurut Budimansyah (2010, hlm. 63), habituasi adalah proses menciptakan aneka situasi dan kondisi (persisten-life situation) yang berisi aneka ragam penguatan (reinforcement) yang memungkinkan, peserta didik pada satuan pendidikannya, di rumah, di lingkungan masyarakatnya, membiasakan diri berperilaku sesuai nilai dan menjadikan perangkat nilai yang telah diinternalisasi dan dipersonalisasi melalui proses olah hati, olah pikir, olah raga, olah rasa dan karsa itu sebagai karakter atau watak.

Pentingnya proses habituasi terhadap nilai-nilai tersebut dilandasi dengan pemikiran Kilpatrick dalam (Megawangi, 2004, hlm. 113) menyatakan bahwa salah satu penyebab ketidakmampuan seseorang untuk berperilaku baik; walaupun secara kognitif mengetahuinya, adalah tidak terlatih untuk melakukan kebajikan atau perbuatan yang bermoral (moral action). Pendapat ini sejalan dengan apa yang diungkapkan oleh Aristoteles dalam (Megawangi, 2004, hlm. 113) bahwa karakter itu erat dengan kaitannya dengan "habit" atau kebiasaan yang terus menerus dilakukan.

Di sisi lain, kebijakan Pemerintah Kota Bandung yang merespon cepat permasalahan lingkungan yang terjadi di daerahnya dapat ditiru oleh kota-kota lain di Indonesia terutama kebijakan atau program yang berwawasan lingkungan. Pendekatan persuasif yang dilakukan pemerintah Kota Bandung dalam membangun kebiasaaan (habit) masyarakat Kota Bandung terhadap pelestarian lingkungan hidup, dengan memanfaatkan keberadaan media sosial adalah suatu langkah yang brilian.

Dewasa ini dunia mirip dengan apa yang dikonseptualisasikan Mc Luhan, dimana kondisi geografis, geografis, kekuatan politik, hukum dan ekonomi negara, semua yang ada adalah hubungan antar manusia atau interfaces. Konseptualisasi Mc Luhan ini benar adanya setelah muncul internet sebagai gawai super cepat dan handal untuk keperluan apapun. Prediksi bahwa interkoneksitas sosial merupakan modal dasar agar jaringan informasi bergerak cepat dan berkembang sudah terbukti dengan maraknya penggunaan media sosial belakangan ini. Dengan kemudahan akses informasi dan murahnya melakukan interkoneksi internet 
membuat hampir setiap orang menggunakan media sosial (Prisgunanto, 2012, hlm. 1).

Media sosial merupakan bentuk dari media kelompok yang ada di media online mempunyai karaktersitik sebagai berikut (Habibullah, 2013, hlm. 20-21):

\section{a. Partisipasi}

Media sosial memberikan kesempatan pada semua orang untuk berkontribusi dan memberikan umpan balik kepada minat tertentu sehingga tidak ada garis antara media dan pemirsa

\section{a. Keterbukaan}

Banyak media sosial terbuka utnuk menerima umpan balik dan partisipasi. Media sosial mendorong voting, komentar, dan berbagi informasi, jarang ada hambatan untuk mengakses dan memanfaatkan konten-konten.

b. Pembicaraan

Media tradisional menyiarkan atau mendsitribusikan kepada pemirsa satu arah sedangkan media sosial melakukan percakapan dua arah. c. Komunitas

Media sosial mengizinkan membentuk komunitas dengan cepat dan merupakan bentuk komunikasi yang efektif. Komunitas dapat berbagi minat, misalnya yang suka fotografi, isu politik, dan acara favorit televisi.

d. Konektivitas

Media sosial dapat menghubungkan dari berbagai sumber daya situs web dan masyarakat.

\section{Pembahasan Berdasarkan Uji Chi Square Penelitian}

Uji chi square merupakan pengujian hipotesis tentang perbandingan antara frekuensi sampel yang benar-benar terjadi (selanjutnya disebut dengan frekuensi observasi) dengan frekuensi harapan yang disarankan atas hipotesis tertentu pada setiap kasus atau data (selanjutnya disebut frekuensi harapan). Dalam penelitian ini, uji chi square dibedakan atas jenis kelamin, jurusan dan 
status pekerjaan orang tua. Berikut adalah pemaparannya.

\section{1) Tabulasi Silang Antara Jenis Kelamin dengan Kesadaran Lingkungan}

Berdasarkan tabel diatas dapat dilihat tabulasi silang antara jenis kelamin dengan kesadaran lingkungan, dengan nilai probablitas 0,589 lebih besar dari 0,05. Sehingga dapat disimpulkan bahwa tidak ada hubungan yang signifikan antara jenis kelamin dengan kesadaran lingkungan

\section{2) Tabulasi Silang antara Jurusan dengan Kesadaran Lingkungan}

Berdasarkan tabel diatas dapat dilihat tabulasi silang antara jurusan dengan kesadaran lingkungan, dengan nilai probablitas 0,230 lebih besar dari 0,05. Sehingga dapat disimpulkan bahwa tidak ada hubungan yang signifikan antara jurusan dengan kesadaran lingkungan.

\section{3) Tabulasi Silang antara Pekerjaan Orang Tua dengan Kesadaran Lingkungan}

Berdasarkan tabel diatas dapat dilihat tabulasi silang antara pekerjaan orangtua dengan kesadaran lingkungan, dengan nilai probablitas 0,390 lebih besar dari 0,05. Sehingga dapat disimpulkan bahwa tidak ada hubungan yang signifikan antara pekerjaan orang tua dengan kesadaran lingkungan.

\section{SIMPULAN}

Berdasarkan sejumlah temuan penelitian yang telah dipaparkan sebelumnya, tampak bahwa habituasi, media sosial dan pembelajaran Pendidikan Kewarganegaraan berpengaruh secara positif dan signifikan dengan kategori tinggi terhadap kesadaran lingkungan di SMA Negeri Se-Kota Bandung. Hal tersebut dikarenakan:

1. Habituasi yang dilaksanakan di sekolah tidak hanya menitikberatkan pada sosialisasi semata, akan tetapi terdapat wujud nyata di lapangan berupa berbagai macam kegiatan habituasi. Macam-macam kegiatan habituasi itu adalah habituasi secara rutin yang dilaksanakan setiap harinya berupa pembersihan lingkungan sekolah, habituasi secara spontan yang dilakukan apabila lingkungan sekolah dirasa tidak kondusif untuk melakukan pembelajaran, habituasi secara teladan yang ditunjukkan dengan keteladanan dewan guru dalam menanamkan sifat-sifat yang mendukung kesadaran lingkungan dan habituasi secara program yang dilakukan berdasarkan program-progam 
yang telah disusun sekolah ataupun pemerintah yang mendukung upaya menumbuhkan kesadaran lingkungan pada siswa misalnya program Green House, Pembuatan Kompos Gerakan Pungut Sampah (GPS) dan lain sebagainya;

2. Pemanfaatan media sosial yang tepat dalam membantu proses habituasi dan pembelajaran Pendidikan Kewarganegaraan sehingga sangat berpengaruh terhadap kesadaran lingkungan siswa. Keberadaaan media sosial saat ini telah mampu dimanfaatkan pihak sekolah dan pemerintah untuk memobilisasi siswa untuk menjaga lingkungannya. Pemanfaatan keberadaan media sosial di sekolah ditunjukkan pihak sekolah yang mampu memanfaatkan keberadaaan konten media sosial dalam mendukung pembelajaran dan mensosialisasikan berbagai macam program-program berwawasan lingkungan. Sedangkan dari pemerintah, keberadaan media sosial digunakan sebagai alat untuk melakukan kampanye persuasif dan mensosialisasikan program-prorgam berwawasan lingkungan terhadap siswa.

\section{Pembelajaran Pendidikan} Kewarganegaraan yang dilaksanakan di sekolah tidak hanya menitikberatkan pada penguasaan materi pembelajaran secara kognitif saja, akan tetapi meliputi pula pada perkembangan sikap dan perilaku siswa. Hal ini dibuktikan dengan pembelajaran Pendidikan Kewarganegaraan yang sudah dilakukan dengan menggunakan metode pembelajaran yang menyenangkan, sehingga mendorong penguatan peran dan kedudukan Pendidikan Kewarganegaraan sebagai bagian dari pendidikan kesadaran lingkungan.

\section{DAFTAR RUJUKAN}

Aswandi. (2010). Membangun Bangsa Melalui Pendidikan Berbasis Karakter, dalam Jurnal Pendidikan Karakter, Publikasi Ilmiah Pendidikan Umum dan Nilai, Vol. 2. No 2 Juli 2010.

Budimansyah, D. (2008). Revitalisasi Pembelajaran PKn melalui Praktik Belajar Kewarganegaraan Project Citizen. Jurnal Acta Civicus, Vol 1 No. 2.

Budimansyah, D. (2010). Penguatan Pendidikan Kewarganegaraan untuk Memhangun Karakter Bangsa. Bandung: Widya Aksara Press.

Darmawan, B, dkk. (2010). "Hubungan Pengetahuan, Sikap, Perilaku dan 
Peran Serta dengan Kesadaran Lingkungan Hidup serta Kesanggupan Membayar Masyarakat Sekitar Bantaran Sungai di Kota Pekanbaru”. Journal of Environmental Science. Program Studi Ilmu Lingkungan PPS Universitas Riau

Djahiri, K. (2006). Pendidikan Nilai Moral dalam Dimensi Pendidikan Kewarganegaraan. Bandung: Laboratorium PKn FPIPS UPI.

Effendi, S dan Tukiran. (2012). Metode Penelitian Survei. Jakarta: LP3ES.

Gurnelius, S. (2011). 30-minute Social Media Marketing. McGraw-Hill Companies, United States.

Habibullah. (2013) Pemanfaatan media sosial untuk usaha kesejahteraan sosial. Jurnal Informasi, Volume 18, No 1, Tahun 2013. Jakarta: Pusat Penelitian dan Pengembangan Kesejahteraan Kementerian Sosial Republik Indonesia

http://bplh.bandung.go.id/v2/gerakanpungut-sampah/

http://news.detik.com/bandung/read/2014/ $\underline{\text { 02/05/172837/2488356/486/ini-inna- }}$ savova-wn-bulgaria-yang-sebutbandung-the-city-of-pigs

http://regional.kompas.com/read/2014/06/ 23/1114368/Ridwan.Kamil.Bikin.Ger akan.Pungut.Sampah.Senin.Rabu.Jum at.

Jamanti, R. (2014). "Pengaruh Berita Banjir di Koran Kaltim terhadap Kesadaran Lingkungan Masyarakat Kelurahan Temindung Permai Samarinda”. eJournal Ilmu Komunikasi. Jurusan Ilmu Komunikasi, Fakultas Ilmu Sosial dan Ilmu Politik, Universitas Mulawarman.

Juditha, C. (2011) Hubungan penggunaan situs jejaring sosial facebook terhadap perilaku remaja di Kota Makassar. Jurnal Penelitian IPTEKKOM Volume 13, No. 1, Juni 2011. Makassar: Balai Besar Pengkajian dan Pengembangan Komunikasi dan Informatika Makassar

Kaplan and Haenlein. (2009). Users of The World, Unite! The Challenges and Opportunities of Social Media. Kelley School of Business, Indiana University.

Keraf, AS. (2006). Etika Lingkungan, Jakarta: Penerbit Buku Kompas, 
Kusnendi. (2008). Model-Model Persamaan Struktural satu dan Multigroup sampel dengan LISREL. Bandung: Alfabeta.

Margono. (2009). Metodologi Penelitian Pendidikan. Jakarta: Rineka Cipta.

Megawangi, R. (2004), Pendidikan Karakter: Solusi yang Tepat Membangun Bangsa. Jakarta: BP Migas.

Neolaka, A. (2008). Kesadaran Lingkungan. Jakarta: Rineka Cipta.

Paladewa, DA. (2013). Motif Penggunaan dan Interaksi Sosial di Twitter (Studi Deskriptif Kualitatif pada Mahasiswa Ilmu Komunikasi FISHUM UIN Sunan Kalijaga Yogyakarta). Skripsi, Fakultas Ilmu Sosial dan Humaniora UIN Sunan Kalijaga Yogyakarta

Prasetyo, AW. (2013). Perlunya Kesadaran Lingkungan terhadap Diri Manusia. Semarang: Jurnal Teknologi Pendidikan, Jurusan Kurikulum dan Teknologi Pendidikan, Fakultas Ilmu Pendidikan, Universitas Negeri Semarang.
Prisgunanto, 1. (2012) Pengaruh Tingkat Kepercayaan Berkomunikasi di Jejaring Sosial Internet (Social Media) Terhadap Perilaku Beli Mahasiswa (Survei Asosiatif Netter Kaskus Mahasiwa Jurusan Teknologi Informasi di beberapa Kampus di Jakarta). Juni 2012 Volume 4, No 1, Tahun 2012. Jakarta: Universitas Multimedia Nusantara

Sapriya dan Winataputra. (2004). Pendidikan Kewarganegaraan: Model Pengembangn Materi dan Pembelajaran, Bandung: Laboratorium PKn FPIPS UPI

Silalahi, U. (2010). Metode Penelitian Sosial. Bandung: PT Refika Aditama.

Siswanto, T. (2013) Optimalisasi sosial media sebagai media pemasaran usaha kecil menengah. Jurnal Liquidity Vol. 2, No. 1, Januari-Juni 2013, hlm. 80-86. Jakarta: Universitas Muhammadiyah Prof Dr Hamka

Soemantri, M.N. (2001). Menggagas Pembaharuan Pendidikan IPS. Bandung: Remadja Rosdakarya. 
Sudibyo, R.S. 2008. Konsep EfSD di Indonesia. Bahan Presentasi. Yogyakarta: Universitas Gadjah Mada.

Sudrajat, E. (2011). "Pengaruh Pembelajaran Pendidikan Kewarganegaraan dan Habituasi terhadap Kesadaran Lingkungan Siswa SMP”. Tesis, SPs UPI: Tidak Diterbitkan.

Syahri, M. (2013). Partisipasi Masyarakat dalam Pembangunan Berkelanjutan Berbasis “Green Moral”. Disertasi, SPs UPI: Tidak Diterbitkan

Tim Penyusun Kamus Pusat Bahasa. (2005). Kamus Besar Bahasa Indonesia, Jakarta: Balai Pustaka.
Watie, EDS. (2011) Komunikasi dan Media Sosial. The Messenger, Volume III, No 1, Edisi Juli 2011. Semarang: Universitas Semarang

Winataputra, US. (2012) Pendidikan Kewarganegaraan dalam Perspektif Pendidikan untuk Mencerdaskan Kehidupan Bangsa (Gagasan, Instrumen, dan Praksis). Bandung: Widya Aksara Press.

Winataputra, dan Budimansyah, (2007). Civic Education: Konteks, Landasan, Bahan Ajar, dan Kultur Kelas. Prodi PKn SPs UPI.

Wiranata, I. (2001). Antropologi Budaya. Bandung: PT. Citra Aditya Bakti 